\title{
Um manuscrito inédito do naturalista José Bonifácio de Andrada e Silva: o parecer sobre o método de desinfetar as cartas vindas de países estrangeiros
}

\author{
An unpublished manuscript from the naturalist José Bonifácio \\ de Andrada e Silva: the document about the method for \\ disinfecting the letters came from foreign countries
}

Alex Gonçalves Varela

Mestre em educação aplicada às geociências pelo Instituto de Geociências da Unicamp Rua Ferreira Viana, 36/502 22210-040 Rio de Janeiro - RJ Brasil

alex@ige.unicamp.br

Maria Margaret Lopes

Professora da Pós-Graduação em educação aplicada às geociências, IGE/Unicamp

Instituto de Geociências,

Caixa Postal 6152

13083-970 Campinas - SP - Brasil

mmlopes@ige.unicamp.br
VARELA, A. G.; LOPES, M. M.: Um manuscrito inédito do naturalista José Bonifácio de Andrada e Silva: o parecer sobre o método de desinfetar as cartas vindas de países estrangeiros. História, Ciências, Saúde - Manguinhos,

v. 13, n. 1, p. 159-68, jan.-mar. 2006.

A trajetória de naturalista do Ilustrado José Bonifácio de Andrada e Silva tem sido pouco explorada pela historiografia. Ele teve uma participação ativa na flustração Portuguesa, atuando em diversas instituiç̃es de pesquisa e ensino. Na Academia Real das Ciências de Lisboa, foi um dos sócios de destaque publicando inúmeras memórias científicas. No campo da química, ganhou relevância o "Parecer sobre o método de desinfetar as cartas vindas de países estrangeiros" (1815), elaborado por uma Comissão de três sócios: José Bonifácio, Francisco Elias Rodrigues da Silveira e Luiz de Siqueira Oliva. Nesse parecer, os autores defenderam a utilização do gás oximuriático (nome arcaico do gás cloro, que supunham conter oxigênio) como o anti-séptico mais eficaz contra os "miasmas da peste e da febre amarela", no lugar do vinagre.

PALAVRAS-CHAVE: José Bonifácio; história das ciências; história da química; história de Portugal; Academia Real das Ciências de Lisboa.

VARELA, A. G.; LOPES, M. M.: An unpublished manuscript from the naturalist José Bonifácio de Andrada e Silva: the document about the method for disinfecting the letters came from foreign countries.

História, Ciências, Saúde - Manouinhos,

v. 13, n. 1, p. 159-68, Jan.-Mar. 2006.

The naturalist profile of the Enlightened José Bonifácio de Andrada e Silva has been few explored by historiography. He had an active part in the Portuguese Enlightenment, actuating in many Research and Teaching Institutions. At the Lisbon Royal Academy of Science he was one of the distinctive members, publishing innumerable scientific memoir. In the field of Chemistry, is relevant the document about the method for disinfecting the letters came from foreign countries (1815), elaborated by a Committee of three members: Jose Bonifácio, Francisco Elias Rodrigues da Silveira e Luiz de Siqueira Oliva. In this paper, they defended the using of oxymuriatic gas (archaic name of the chlorine gas) as the most efficient antiseptic against "the miasmas of the plague and yellow fever" instead of vinegar.

KEYWORDS: José Bonifácio; history of science; history of chemistry; Portuguese history; Lisbon Royal Academy of Science. 
Os estudos no campo da História das Ciências, no contexto do Império Colonial Português entre o final do século XVIII e o início do século XIX, encontram em José Bonifácio de Andrada e Silva um cientista apropriado e amplas perspectivas de trabalho. Expressiva parte da bibliografia sobre sua trajetória destaca somente o viés político, como estadista e parlamentar, e não incorpora a análise de sua dimensão de naturalista.

Em Portugal, José Bonifácio desenvolveu inúmeras atividades científicas em instituições de pesquisa e de ensino. Ele formou-se na Universidade de Coimbra, participou de viagens científicas a pedido do governo português por importantes áreas de mineração da Europa Central e do Norte, foi sócio da Academia Real das Ciências de Lisboa, publicou diversas memórias no âmbito da história natural e administrou espaços governamentais ligados diretamente à mineração, como a Intendência Geral das Minas e Metais do Reino. Portanto, em que pese a densidade da bibliografia a seu respeito, há lacunas que estimulam a reflexão em novas direções.

A atuação do Ilustrado José Bonifácio em Portugal está relacionada a um momento bastante específico das relações entre Portugal e Brasil no final do século XVIII e no início do século XIX. As transformações provocadas pela Revolução Industrial e pela Revolução Francesa e a conseqüente crise do Antigo Sistema Colonial tornou obrigatório promover reformas profundas. Essas reformas, segundo os dirigentes lusos, visavam superar a defasagem econômica frente a países como a Inglaterra e a França, entre outros, evitando assim a perda dos seus domínios ultramarinos, sobretudo o Brasil, para outras potências européias.

As reformas promovidas pelo Estado português tiveram início no governo de D. José I, com o seu todo-poderoso ministro, o Marquês de Pombal, e foram reforçadas no governo de D. Maria I, mais especificamente por meio do principal 'homem da viradeira', o ministro D. Rodrigo de Sousa Coutinho. Ao seu lado foram cooptados vários estudiosos, das mais diversas partes do Império ultramarino. Ganharam destaque os naturalistas da Academia Real das Ciências de Lisboa, instituição científica portuguesa que orientou as pesquisas com o intuito de reconhecer e explorar as 'produções naturais' do Reino e de todo o império português. Essa articulação entre o Estado e as instituições científicas também ocorreu por meio da Universidade de Coimbra, que ajudou a difundir as 'luzes da razão e do progresso' pela nação lusa.

Entre os naturalistas da Academia Real das Ciências de Lisboa que foram arregimentados pelo Estado português para desempenhar papel ativo nessa política de reformas encontra-se José Bonifácio de Andrada e Silva. Ele ingressou na Universidade de Coimbra no ano de 1780, nos cursos de Direito Canônico e Filosofia Natural. Nesse espaço universitário, ele e os seus dois irmãos, todos mem- 
bros da elite colonial, juntaram-se às elites cultas da metrópole que ali estudavam, onde juntos leriam as mesmas obras e receberiam a mesma formação (Nizza da Silva, 1999).

José Bonifácio ingressou na Faculdade de Filosofia, entidade criada no conjunto das reformas pombalinas com o objetivo de ensinar as Ciências Naturais e as Ciências Físico-Químicas, tendo o curso a duração de quatro anos. Não havia nenhum curso preparatório, e, sobressaíam os compêndios de Antonio Genovese, Carl von Linné, Petrus von Musschenbroek, e a História Natural de Plínio.

Durante o período em que esteve na Universidade, José Bonifácio recebeu uma ampla formação. Na Faculdade de Direito, cursou as cadeiras de Direito Natural, História do Direito Civil Romano e Português, Elementos de Direito Romano, Elementos de Direito Canônico, Direito Civil Pátrio e Jurisprudência. Na Faculdade de Filosofia, cursou as cadeiras de História Natural, Física Experimental, Química Teórica e Prática. E, na Faculdade Matemática, freqüentou o curso de Geometria.

Após receber o grau de bacharel, José Bonifácio conseguiu entrar para a Academia Real das Ciências, sendo logo agraciado com uma pensão real para participar de uma 'viagem filosófica' por diversos países da Europa Central e do Norte com o intuito de obter os modernos conhecimentos mineralógicos. Essa viagem complementou a formação recebida em Coimbra e especializou as atividades profissionais do jovem, que se tornaria, como ele próprio afirmava, um 'metalurgista de profissão'. Tal especialização possibilitou o convite feito por D. Rodrigo para Bonifácio ser Professor da Cadeira de Metalurgia da Universidade de Coimbra (Carta Régia de 15.04.1801) e dirigir a Intendência Geral das Minas e Metais do Reino (Carta Régia de 18.05.1801).

Ao retornar a Portugal, José Bonifácio realizou atividades de pesquisa em várias instituições científicas como a Casa da Moeda de Lisboa - tendo sido nomeado por Carta Régia de 12 de novembro de 1801 diretor de um Curso de Docimástica e autorizado a abrir um laboratório na mesma instituição - e a Academia Real das Ciências de Lisboa. Neste último espaço, realizou diversos estudos sobre as 'produções naturais' da colônia e do Reino, que deram origem a importantes Memórias científicas. Nesse espaço de sociabilidade e produção intelectual, Bonifácio realizou dois estudos no campo da química. O primeiro estudo foi a "Memória Química sobre a Quina do Rio de Janeiro", elaborada em 1814, juntamente com João Croft, Bernardino Antonio Gomes e Sebastião Francisco de Mendo Trigozo (Filgueiras, 1986).

Um outro trabalho de José Bonifácio no mesmo campo científico foi o "Parecer sobre o método de desinfetar as cartas vindas de países estrangeiros". A realização de tal pesquisa ocorreu em função do Aviso de 19 de setembro de 1814 expedido pela Secretaria de 
Estado dos Negócios da Guerra e da Marinha. Nesse Aviso, o monarca português pediu à Academia Real das Ciências o seu parecer sobre o método que deveria ser seguido para desinfetar as cartas vindas de países estrangeiros "contagiados ou suspeitos de peste, ou de febre amarela".

A Academia nomeou uma Comissão de três dos seus sócios para examinar a matéria e apresentar o seu voto. Os três acadêmicos foram: José Bonifácio de Andrada e Silva, Luiz de Siqueira Oliva (que não teve a honra de assinar o parecer, uma vez que faleceu dias antes de concluir-se sua redação) e Francisco Elias Rodrigues da Silveira.

Tal parecer nunca foi publicado, pois a Comissão não julgou necessário fazer uma dissertação "miúda e científica, para expender e corroborar o seu voto". Contudo, eles garantiram que o trabalho era o resultado de "maduros e longos exames baseados em princípios e experiências". O parecer final foi dado pela Secretaria da Academia Real das Ciências de Lisboa no dia 8 de julho de 1815.

A pesquisa sobre o método de desinfetar as cartas vindas de fora está inserida num debate científico iniciado em 1813 por Charles Stuart, ministro da Coroa Britânica em Lisboa, que reclamou a substituição do método desinfetante em vigor por novas técnicas que materializassem o poder da nova química, dispensando assim a abertura das cartas. O método desinfetante que vinha sendo aplicado à correspondência seguia as disposições do Regimento do Porto de Belém e o denominado Regimento da Peste, ambos publicados em 1695, e que envolviam o indesejável pré-requisito de abertura e desdobramento das cartas. A discórdia, que começou por dividir os membros da Junta de Saúde Pública, cedo se estenderia à Academia de Ciências, culminando por fim nas páginas do Jornal de Coimbra (Duarte \& Dias, 2000, p. 115-6).

Nesse parecer, a comissão analisou dois pontos:

$1^{0}$ se era necessário abrir as cartas vindas de países estrangeiros e passá-las por vinagre para serem desinfetadas;

$2^{\mathrm{o}}$ se as cartas poderiam ser desinfetadas sem serem abertas por meio de alguma fumigação anticontagiosa, e qual deveria ser ela.

Sobre o primeiro ponto, a Comissão não negou a utilidade da antiga prática dos Lazaretos, que se serviam de vinagre (ácido acético) como desinfetante das cartas, e seguiam, nesse caso, as idéias de Guyton de Morveau (1737-1816), que aprovava o uso do vinagre. Contudo, os estudiosos argumentaram que a química moderna - ou seja, aquela que seguia os princípios de Lavoisier - havia descoberto ácidos mais poderosos e ativos, e, portanto, não havia motivo algum para ainda utilizar exclusivamente o vinagre. Eles consideraram que o vinagre ao ser passado nas cartas tinha o incon- 
veniente de ir progressivamente perdendo a sua virtude, reduzindose a "um fleugma inativo e sem préstimo". Havendo, então, ácidos mais poderosos que o vinagre, que penetravam as cartas em fumigações sem que elas fossem abertas, julgaram pois que não era necessário, nem conveniente, tal método.

Antes de passarmos diretamente para o segundo ponto, cabe destacar a idéia de contágio presente no início do século XIX. O conceito básico de contágio era o de transmissão de uma doença a partir de estímulos provenientes do mundo externo e do contato de uma pessoa doente com a outra. Admitia-se o contágio pelo contato direto, pelo ar e por meio de objetos materiais (roupas, móveis e cartas, entre outros) que servissem de intermediários. A noção de contágio associava a doença ao contato e ao sentido do tato e do olfato. Não se imaginava até esse momento que pudesse haver transmissão de enfermidades, por exemplo, pela água ou por um agente microbiológico. Somente com o aparecimento do conceito de transmissão foi que a propagação das epidemias se deslocou dos imprecisos sentidos do olfato e do tato para o da visão (Czresnia, 1997, p. 59).

As práticas de desinfecção e de fumigamento, como por exemplo, a de desinfetar as cartas vindas de países estrangeiros que pudessem estar contagiadas por miasmas das pestes, estavam relacionadas à idéia do contágio. O receptor, antes de abrir a carta que lhe havia sido endereçada, deveria ter o cuidado de desinfetá-la, neutralizando com um anti-séptico o possível miasma. Essa era uma típica atitude associada à concepção de que as enfermidades eram adquiridas por meio dos sentidos - não tinham uma correspondência no corpo, não eram identificadas como lesão em um órgão (ibidem, p. 59).

Quanto ao $2^{\underline{0}}$ ponto da Memória, ou seja, a averiguação da possibilidade de desinfetar as cartas sem serem abertas por meio de alguma fumigação anticontagiosa, definindo-se qual deveria ser esta, fato que já havia ficado em parte respondido, a comissão acrescentou algumas observações.

A primeira dizia respeito ao fato de os gases sulfuroso, muriático e oximuriático, quando atravessavam as cartas fechadas, alterarem as letras, sobretudo quando estas eram expostas por algum tempo em aparelho próprio aos seus vapores. Ora, se isso ocorria com cartas fechadas, estas ao serem golpeadas produziriam gases, o que não deveria ser feito para maior segurança, como propuseram os integrantes da Comissão. Todos os gases aqui citados eram desinfetantes e penetrantes; assim, ficava claro que qualquer um deles era próprio para o fim, sem ser preciso romper o sigilo das cartas, nem molhar o papel.

Em segundo lugar, os autores do Parecer argumentaram que as cartas não eram suscetíveis de conservar com vigor os "miasmas 
pútridos contagiosos", e, caso os conservassem, muito pequeno deveria ser o número dessas partículas, e a sua força, podendo pois ser destruídas por qualquer gás ácido. Em função dessa averiguação, os sócios que compunham a Comissão concluíram não ter sido propagada "peste do levante ou febre amarela" por meio das cartas.

Cabe mencionar que essa preocupação em descobrir meios que pudessem combater os efeitos nocivos dos miasmas era recorrente no século XVIII. A teoria dos miasmas explicava não apenas as enfermidades dos pântanos, mas também as doenças produzidas por cheiros de coisas estragadas e pútridas. A malignidade do ar provinha de emanações pútridas (Kury, 1990). No final do século XVIII, as idéias sobre miasmas e sobre a transmissão de enfermidades pelo ar deixaram de ser apenas hipóteses. A idéia de que o ar poderia conter substâncias maléficas ganhou bastante apoio nesse momento. Começou-se, então, a descobrir novas substâncias capazes de impedir a putrefação e que deviam ser também capazes de destruir os miasmas. Entre os estudiosos dos chamados anti-sépticos estavam Louis Bernard e Guyton de Morveau, este último companheiro de pesquisas de Lavoisier, que estudou ácidos minerais em forma gasosa e recomendava o ácido muriático oxigenado como meio de destruir os vapores nocivos.

Entre os gases anti-sépticos o mais poderoso, segundo os membros da Comissão, era o "gás oximuriático", por ser considerado o mais comburente. Além disso era o mais expansivo e elástico, podendo em brevíssimo tempo encher grandes espaços, sobretudo quando agia seco e concentrado. Como os "miasmas da peste e da febre amarela" eram substâncias combustíveis, deveriam ser destruídas pelo "gás oximuriático". Isso se comprovava na prática: para se evitar a difusão de qualquer moléstia contagiosa, era preciso mandar queimar todas as coisas e matérias infectadas. Esses fatos levaram os membros da Comissão a se interrogarem sobre o uso efetivo do vinagre como um anti-séptico e a preferir o "gás oximuriático", elemento da química moderna.

Os membros da Comissão concluíram que o gás oximuriático era o mais poderoso desinfetante conhecido, concordando assim com Morveau. Por isso, eles julgaram que em todos os casos nos quais houvesse certeza de peste ou febre amarela violenta, sempre deveria ser usado esse gás em preferência a qualquer outro, ainda mesmo para a desinfecção das cartas.

Cabe registrar que no Parecer os nomes dos ácidos em forma de gases seguia a nova nomenclatura química estabelecida por Lavoisier. Eles usaram gás sulfuroso, gás muriático e oximuriático. A terminologia muriático foi estabelecida no Método de Nomenclatura Química (1787), obra coletiva elaborada por Lavoisier, Berthollet, Morveau e Fourcroy, para substituir o ácido de sal marinho, também chamado espírito de sal (Bensaude-Vincent \&Stengers, 1996, p. 128-31). 
Vale ressaltar que o gás muriático, hoje cloreto de hidrogênio, foi objeto de grande controvérsia após a morte de Antoine Laurent Lavoisier (1743-1794). Ele tem propriedades ácidas e reage violentamente com a água, originando uma solução altamente ácida, o ácido muriático (hoje ácido clorídrico, elemento cloro). Ora, nem o gás muriático nem o ácido dele resultante contém oxigênio, como acreditava o químico francês. Os químicos que sucederam a Lavoisier tentaram descobrir oxigênio nesses compostos, mas foi em vão. Após vários debates, concluiu-se que nem todos os ácidos continham oxigênio (ibidem, p. 128-31).

Poucos anos separavam a elaboração desse parecer pela Comissão constituída pelos três sócios da Academia e a descoberta por $\mathrm{H}$. Davy, em 1808, de que o 'ácido muriático oxigenado' era um elemento - que recebeu o nome de cloro. Por isso, seria incorreto considerá-los afastados das principais transformações que vinham ocorrendo no campo da química, pois esse era um momento de transição entre a 'velha' e a 'nova' química.

\section{REFERÊNCIAS BIBLIOGRÁFICAS}

Bensaude-Vincent, Bernadette; Stengers, Isabelle

$$
1996
$$

Czresnia, Dina 1997

Duarte, António Groen; Dias, José Pedro de Sousa 2000

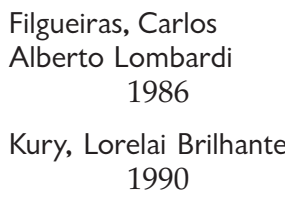

Nizza da Silva,

Maria Beatriz 1999

Varela, Alex Gonçalves 2001
História da química. Portugal: Instituto Piaget.

Do contágio à transmissão: ciência e cultura na gênese do conhecimento epistemológico. Rio de Janeiro: Ed. Fiocruz.

A segurança da inocência do papel: a desinfecção da correspondência em Portugal (1637-1897). In: Congresso Luso-Brasileiro de História da Ciência e da Técnica (I). Livro de Resumos. Évora: Comissão Organizadora do Congresso - Centro de Estudos de História e Filosofia da Ciência da Universidade de Évora.

A química de José Bonifácio.

Química Nova, n. 9, out.

O império dos miasmas: a Academia Imperial de Medicina (1830-1850).

Dissertação de Mestrado, Departamento de História,

Universidade Federal Fluminense, Niterói.

A cultura luso-brasileira: da reforma da Universidade à Independência do Brasil. Lisboa: Ed. Estampa.

Juro-lhe pela honra de bom vassalo e bom português: filósofo natural e homem público - uma análise das memórias científicas do ilustrado José Bonifácio de Andrada e Silva (1780-1819). Dissertação de Mestrado, DGAE/IG/Unicamp, Campinas (SP).

Recebido para publicação em junho de 2005. Aprovado para publicação em agosto de 2006. 


\title{
Paxecen solve o método de desinfetar as cartas vindas de paises estrangeiros
}

\author{
Localiração: Atrquivo O Vacional da Torre do Tombo \\ Ollinistério do Reino. \\ Clegócios da Paide Publica. 1814, Ollaço 970, Caixa 1085.
}

Pox ethiso de 19 de setembro de 1814 expedido pela Secretaria de Estado dos CVegócios da

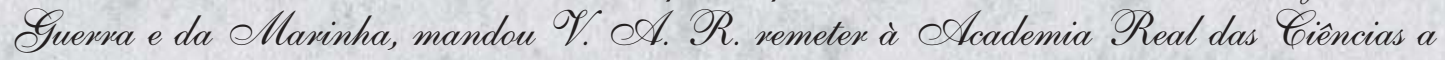

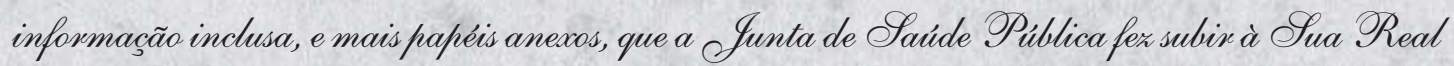
Presença, sobre o método de desinfetax as cartas vindas de paises estrangeiros contagiados ou suspeitos de preste, on de febre amavela, para que a etcademia desse o seu voto sobre método que se devená seguix a este respicito.

Em conseqüência nomeou a Etcademia uma Comissão de três dos seus sócios paxa examinavem com madusera, e tempo necessásio, a matéria, e apresentarem depois o seu voto, o qual têm a honsa os comissávios existentes, por tex monnido o tenceivo Luir de Siqueira Oliva sem poder assinars, de - levar agona à Presenca de \%. OA. भR.

eA Comissão nomeada de três sócios não julga necessávio far ex uma dissentação muida e cientifica,

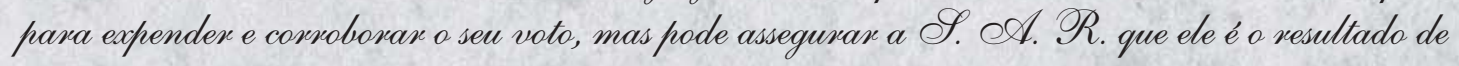
maduros e largos exames fundados em principios e experiencias.

Dois são os pontos sobre que devemos dax o nosso voto: 10 Oe é necessário abrix as cantas e passáLas pon vinagre para se desinfetarem. $2^{\circ}$ Se se podem desinfetar sem sex abertas por meia de alguma fumigação anticontagiosa, e qual ela deva sex.

Sobre o primeiro ponto dissemos, que não negamos a utilidade da antiga prática dos Laravetos, que se semsiam de vinagre como desinfetante das cartas; e com efeito ONomean aprove o vinagre nesse caso. ONas tendo a quimica moderna descoberto hoje em dia ácidos mais poderosos e ativos, não há motivo para se usax exchusivamente do vinagre, nem a prática antiga dos Laravetos pode provar contra os outros agentes novos, porque então não evam conhecidas as suas virtudes. Demais, se a experiencia far a favor do vinagre, para a peste levantina, não o far para a febre amavela, em que não ha experiència alguma a seu favox. EAlem disto o vinagre pox onde se passam tem o inconveniente de que vai progressivamente perdendo a sua virtude, vedurindo-se a uma fleugma inativa e sem préstimo.

Tudo o que se tiva com centera quimica dos antigos contra os contágios, é que em todos eles se usavam ou se produriam acidos vegetais ou minevais, e ainda o método ordinávio de farex grandes 
fogueiras, não podia sex uitil, se não porque formava uma grande posção de ácido carbionico, que sendo um bom anti-septico se espathava pela atmosfera. O mesmo se cothe do antigo uso de queimar - ensofre, de que já se far menção no lirro de Lob, e em outros autores gregos e romanos. OHavendo pois ácidos mais poderosos que o vinagre que prenetram em fumigaçôes as cartas sem que estas se abram, bastando somente golpeá-las devidamente para maion segurança, não há motivo algum para as abriremos, e molha-las em vinagre. Sulgamos pois que não épreciso, nem conveniente tal método, nem ele se pratica em Clatta, nem em Leorne, onde as cartas não se abrem, não se golpeiam, nem se passam pelo vinagre, e só são perfumadas em caixa fumigatória. Em Ellassetha, modernamente também não se abrem as cantas, mas só se expurgam pela fumigaça do gás oximusiatico.

Passando ao 20 ponto, se se podem desinfetax sem sex abentas pox meio de alguma fumigaça anticontagiosa, e qual ela deva ser, jä fica em parte respondido; mas acrescentaremos o seguinte.

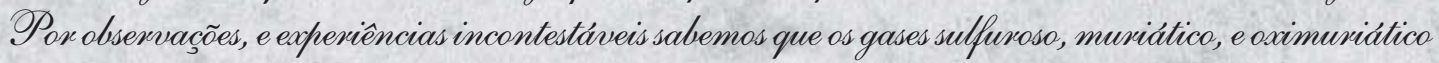
atravessam as cartas fechadas, e alteram mais ou menos as letras, quando as cartas são expostas pox algum tempo em aparelho propprio aos seus vaposes. Ora se isso sucede com cartas fechadas, de certo efeito produrisano gases quando estas forem golpeadas, como para maiox segurança propusemos. Qualquer pois que seja o gás dentre estes, de que se lance mão, como todos são desinfetantes e ponetrantes, fica clavo, que qualquex deles é próppio para o nosso fim, sem sex preciso rompen o sigilo das cantas, nem mothax papel. Demais, sendo a canta pedaços de papel escritos com tinta composta de principios adstringentes vegetais, ácido sulfürico, e de óxido de ferro, todos anti-sépticos éo papel constando de fibra lenhosa ja perfeitamente branqueada, isto é, oxigenada; parece pox isso que as cantas não são suscetiveis de consemvax em vigox os miasmas puitridos contagiosos, e caso os conservem, menox deve sex o numero destas particulas, e a sua força; a qual então pode sen destruida pon qualquen gás ácido. Daqui vem tatver a não haver fato decisivo e contestado, de se ter propagado a pele do levante, ou febre amasela pos meio de castas.

Poxém entre os gases anti-sépticos o mais poderoso até agona conhecido é o gás oximusiático, pox sex o mais comburente, e além disto o mais expansivo e elastico, podendo em brevissimo tempo enchen grandissimos espacos, sobretudo quando obra seco e concentrado: seja, os miasmas da peste e da febre amavela especificamente diferentes, ou comoé mais proviavel, modificações de uma mesma substancia, é hoje conhecido que estes miasmas pestilenciais são de origem animal, produtos tatven de fermentaçôes mais ou menos puitridas. Como todas estas substancias são combustiveis, devem ser destruidas pelo gás oximusiatico. (O) mesmo comprovera a prática, que pasa se evitax a difusão de qualquen moléstia contagiosa manda queimax todas as coisas, e matérias infectadas. Oe o vinagre que é um ácido fraco epouco ativo em comparação deste gás, desinfeta as matérias contagiadas que pox ele se passam; como não será desinfetante o gás oximusiatico, que é sobremancira ativo e comburente, e que destrói radicalmente os sabores, as cores, e os cheiros mais infectos e virulentos? Como não será ele capar de desinfetar as cartas, se tanta virtude tem contra as febres podres e matignas, contra as Epirootias, 
contra as disenterias malignas, e ate destruindo as qualidades da cicuta e do oppio? Que este gás seja um grande remédio para a febre amarela, conta das experiencias feitas por Laborde em Filadélfia, e pelos médicos espanhois. Ë verdade que não hà experiencia dirceta sobre a peste do Levante, mas o Dr. Ollac Evregor no Egito usou com proveito dos vapores do gús muxiatico contra a peste: ora se o ácido muxiático simples foi tão proveitoso, como o não será o gás oximuriático tão enérgico e anti-séptico? Como vesistivão os miasmas da preste, que tahver obrem sobre a economia animal como os fermentos, a ação comburente, e depois neutratirante deste poderoso gás? $\mathscr{P}_{0 x}$ isso, o célebre OKlaproth no seu novo Dicionánio de Duimica afirma que o ácido oximuiniático é o mais poderoso meio para o contágio da peste, e outras quaisquer molestias contagiosas. EAlém disso, se conforme as expexiências de Bomaxini e outros, basta para destruin os miasmas da peste, expon as matérias infectas à corrente do ax atmosferico pon algum tempo, de cento a exposiça e contato do gás oximusiatico que obra instantaneamente com suma energia, deverá sex muito mais conveniente.

Fica pois patente que temos exposto, que o gás oximuxiatico é o mais poderoso desinfetante conhecido ou obre ele queimando e decompondo o bleo volatil, que segundo algum, constitui os miasmas contagiosos; ou apoderando-se do hidrogênio que combinado com outros principios an imais forma os miasmas, ou dá amoniaco, que suspeita Guiton seráa a causa do contágio, ou de qualquex outra materia desconhecida. Pox isto julgamos que em todos os casos em que houvex centera de peste ou felse amaxela videnta, semprese se deverá deitax mão deste gás em preferência a qualquex outro, ainda mesmo paxa a desinfecção das cartas: nos casos porém menos arriscados, e só de segunança julgamos que as fumigaç̃es propostas peto Dx. Bernandino Antonio Oomes serva bastantes pon sevem mais baratas e prontas; haverão porém a precaucão de golpean as cartas pelos lados, para melhox e mais depressa possam sex penetradas pox aqueles vapores, sem alterax a escritura.

Secretaria da OAcademia Real das Cièncias de Lisboa, 08/07/1815. Francisco Elias ORodrigues da Silveira e Oosé Bonifacio de eAlndrada e Silva. 